\title{
Ascites from ovarian cancer patients stimulates MUC16 mucin expression and secretion in human peritoneal mesothelial cells through an Akt-dependent pathway
}

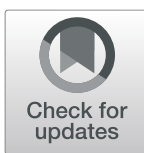

Isabelle Matte ${ }^{1}$, Perrine Garde-Granger ${ }^{2}$, Paul Bessette ${ }^{3}$ and Alain Piché ${ }^{1 *}$

\begin{abstract}
Background: CA125 is a well-established ovarian cancer (OC) serum biomarker. The CA125 heavily glycosylated epitope is carried by the MUC16 mucin, a high molecular weight transmembrane mucin. Upon proteolytic cleavage, the extracellular domain of MUC16 is released from the cell surface into malignant ascites and blood vessels. Previous studies have shown that both tumor and surrounding mesothelial cells may express MUC16. Although little is known about the regulation of MUC16 expression in these cells, recent evidence suggest that inflammatory cytokines may stimulate MUC16 expression. Because malignant ascites is a pro-inflammatory environment, we investigated whether $O C$ ascites stimulate the expression and release of MUC16 by human peritoneal mesothelial cells (HPMCs).
\end{abstract}

Methods: HPMCs were isolated from peritoneal lavages of women operated for conditions other than cancer. MUC16 protein expression was determined by immunoblot, immunofluorescence or immunohistochemistry depending on the experiments. The release of MUC16 from the cell surface was measured using EIA and MUC16 mRNA expression by ddPCR.

Results: We show that high-grade serous ascites from patients with $O C(n=5)$ enhance MUC16 expression in HPMCs. Malignant ascites, but not benign peritoneal fluids, stimulate the release of MUC16 in HPMCs in a dosedependent manner, which is abrogated by heat inactivation. Moreover, we establish that ascites-induced MUC16 expression occurs at the post-transcriptional level and demonstrate that ascites-induced MUC16 expression is mediated, at least partially, through an Akt-dependent pathway. A cytokine array identified upregulation of several cytokines and chemokines in ascites that mediate MUC16 upregulation versus those that do not, including CCL7, CCL8, CCL16, CCL20, CXCL1, IL-6, IL-10, HGF and IL-1 R4. However, when individually tested, none of these factors affected MUC16 expression or secretion. Concentrations of CA125 in the serum of a given patient did not correlate with the ability of its corresponding ascites to stimulate MUC16 release in HPMCs.

Conclusions: Collectively, these data indicate that mesothelial cells are an important source of MUC16 in the context of ovarian cancer and malignant ascites is a strong modulator of MUC16 expression in HPMCs and uncover the Akt pathway as a driving factor for upregulation of MUC16. Factors in ascites associated with enhanced MUC16 expression and release remains to be identified.

Keywords: Ascites, Ovarian cancer, MUC16, Mesothelial cells

\footnotetext{
* Correspondence: alain.piche@usherbrooke.ca

'Département de Microbiologie et Infectiologie, Université de Sherbrooke,

3001, 12ième Avenue Nord, Sherbrooke, Québec J1H 5N4, Canada

Full list of author information is available at the end of the article
}

(c) The Author(s). 2019 Open Access This article is distributed under the terms of the Creative Commons Attribution 4.0 International License (http://creativecommons.org/licenses/by/4.0/), which permits unrestricted use, distribution, and reproduction in any medium, provided you give appropriate credit to the original author(s) and the source, provide a link to the Creative Commons license, and indicate if changes were made. The Creative Commons Public Domain Dedication waiver (http://creativecommons.org/publicdomain/zero/1.0/) applies to the data made available in this article, unless otherwise stated. 


\section{Background}

The tumor-associated antigen CA125, encoded by the MUC16 gene, is detectable in the sera of most women with high-grade serous ovarian carcinomas (HGSOC) [1]. CA125 is an epitope located on a repeated extracellular domain of MUC16 protein [2-5]. Rising and falling levels of serum CA125 correlate with HGSOC progression and regression, making CA125 the most important clinical biomarker for this disease [6-8]. The MUC16 extracellular central domain contains $>60$ glycosylated tandem repeated sequences (156 amino acid). MUC16 C-terminal domain (CTD) contains a unique extracellular region, a transmembrane domain as well as a short 31 amino acid cytoplasmic tail (CT) [2-5]. The ectodomain of MUC16 appeared to be released by metalloproteases (MMPs) and neutrophil elastases (NE) [9, 10]. However, the involvement of these enzymes in MUC16 cell surface cleavage is controversial [11].

Mucins normally function to protect and lubricate the epithelium but alterations of MUC16 expression or glycosylation have been associated with the development and progression of ovarian carcinoma [12-14]. Specifically, we showed that MUC16 knockdown in ovarian cancer cells significantly decreased tumorigenicity, whereas the enforced expression of MUC16 C-terminal domain (last 284 C-terminal residues) enhanced soft agar colony formation and tumor growth in nude mice [13]. Others have confirmed these data by showing that MUC16 knockdown in overexpressing breast or pancreatic cancer cell lines decreased cell proliferation and in vivo tumor growth [15-18]. MUC16 expression can also protect cells from the action of cytotoxic drugs [19, 20]. Furthermore, expression of MUC16 C-terminal domain induces oncogenic transformation of NIH3T3 cells [14]. The ectodomain of MUC16 may have an immunoprotective effect through its interaction with NK cell inhibitory receptor Siglec-9. Binding to Siglec-9 inhibits the interaction between NK cells and cancer cells required for NK-induced cytolysis [21].

Although MUC16 is an oncogene that plays an important role in the development and progression of ovarian cancer, the regulation of MUC16 expression is not well characterized. The expression of MUC16 is not restricted to tumor cells. It is also expressed by the mesothelial cells lining of the adult pleura, pericardium, and peritoneum $[22,23]$. Human peritoneal mesothelial cells (HPMCs) have been reported to be the major source of MUC16 found in the sera of ovarian cancer patients [24]. Secretion of MUC16 in the supernatant of HPMCs was found to be about 5 -fold that of ovarian cancer cell lines [24]. The concentration of MUC16 in peritoneal dialysis effluent has been used for many years as a biomarker for mesothelial cell mass in patients on peritoneal dialysis, which suggest that MUC16 expression is associated with areas of inflammation [25]. Furthermore, MUC16 expression is often increased in non-malignant inflammatory conditions [26-29]. Indeed, cytokines such IL-1 $\beta$, IL-6, IL-8, IL-17, TNF $\alpha$ and IFN $\gamma$ have been shown to alter the expression of MUC16. However, the regulation of MUC16 expression by inflammatory cytokines may differ between HPMCs and tumor cells. For example, IL-1 $\beta$ or TNF $\alpha$ treatment of HPMCs resulted in a significant reduction of MUC16 release whereas IFNy did not influence the shedding of MUC16 in HPMCs [24]. In contrast, TNF $\alpha$ and IFN $\gamma$ stimulated MUC16 mRNA levels in tumor cells, a process that was, at least partly, NF- $\mathrm{B}$ dependent [26].

Because ovarian cancer ascites is an inflammatory environment that contains a variety of cytokines, chemokines and growth factors [30-32], we hypothesized that ascites could stimulate the expression of MUC16 and its release by HPMCs. The goal of this study was therefore to assess the effect of ascites on MUC16 expression in HPMCs. Given the role of MUC16 in ovarian cancer progression, identifying factors that regulates its expression may provide new avenues for ovarian cancer treatment.

\section{Methods}

\section{Cell culture, clinical samples and reagents}

Ascites was routinely obtained at the time of the debulking surgery of ovarian cancer patients treated at the Centre Hospitalier Universitaire de Sherbrooke. Peritoneal fluids were centrifuged at $1000 \mathrm{rpm}$ for $15 \mathrm{~min}$ and cell-free supernatants were stored at $-80{ }^{\circ} \mathrm{C}$ until assayed. All acellular fluids were supplied by the Banque de tissus et de données of the Réseau de Recherche en Cancer of the Fonds de la Recherche du Québec en Santé affiliated to the Canadian Tumor Repository Network (CTRNet). This study was approved by the Institutional Review Board of the Centre de Recherche du CHUS. Informed written consent was obtained from women that underwent surgery by the gynecologic oncology service between 2000 and 2017. All samples were reviewed by an experienced pathologist. Baseline characteristics and serum CA125 levels were collected for all patients. Patients (range 36-76 years) were staged according to the criteria of the International Federation of Gynecology and Obstetrics (FIGO). The ascites characteristics are shown in Table 1. Peritoneal fluids OV401 and OV437 were obtained from benign gynecological conditions including a fibroma and a serous cystadenoma respectively.

HPMCs were isolated from peritoneal lavages of women operated for conditions other than cancer. HPMCs were grown in DMEM/F12 supplemented with $0.4 \mu \mathrm{g} / \mathrm{ml}$ of hydrocortisone (Sigma, Oakville, Canada), 10\% EGF (Sigma, Oakville, Canada), and 10\% FBS and 
Table 1 Ascites characteristics

\begin{tabular}{lllllll}
\hline Ascites & Sub-type & Stage & Grade & Optimal reduction & Chemotherapy before debulking surgery & MUC16 levels in ascites at baseline (KIU/ml) \\
\hline OVC346 & Serous & $3 C$ & 3 & Yes & No & 7146 \\
OVC439 & Serous & $3 C$ & 3 & Yes & No & 3453 \\
OVC508 & Serous & 4 & 3 & Yes & No & 100,000 \\
OVC509 & Serous & 4 & 2 & Yes & No & 1409 \\
OVC690 & Serous & 2B & 3 & Yes & No & 4463 \\
\hline
\end{tabular}

antibiotics (penicillin and streptomycin). The media was changed every 3 days while cells were maintained at $37^{\circ}$ $\mathrm{C}$ in a humidified $5 \% \mathrm{CO}_{2}$ incubator. The nature of HPMCs was confirmed by immunostaining with antibodies against calretinin (Life Technologies, Burlington, ON), N-cadherin, vimentin, smooth muscle actin (Santa Cruz Biotechnology Inc., Santa Cruz, CA), E-cadherin (BD Biosciences). HPMCs stained positive for mesenchymal markers such as vimentin, smooth muscle actin and for calretinin, a specific mesothelial marker. HPMCs were negative for the epithelial markers MOC31 and E-cadherin (data not shown). The OVCAR3 human ovarian cancer cell line was obtained in 2002 from the American Type Culture Collection (Manassas, VA). OVCAR3 cells were grown in RPMI 1640 (Wisent) supplemented with $20 \%$ heat-inactivated FBS (Wisent), 2 $\mathrm{mM}$ L-glutamine (Wisent), 100 units $/ \mathrm{ml}$ penicillin, $100 \mu \mathrm{g} / \mathrm{ml}$ streptomycin and $10 \mu \mathrm{g} / \mathrm{ml}$ insulin, and maintained at $37^{\circ} \mathrm{C}$ in a humidified $5 \% \mathrm{CO}_{2}$ incubator. Cells were tested regularly for mycoplasma contamination.

\section{Immunofluorescence and immunohistochemistry}

OVCAR3 cell line and HPMCs were grown on glass slides. The cells were washed 3 times before a $24 \mathrm{~h}$ treatment with ascites, benign fluid or TNF $\alpha$ (Cell Signaling Technology, Danvers, MA) in serum- and hormone-free DMEM/F12 supplemented with antibiotics and glutamine. Glass slides were then washed in cold PBS and fixed in $3.7 \%$ formaldehyde $20 \mathrm{~min}$ at $4{ }^{\circ} \mathrm{C}$. Glass slides were next rinsed $5 \mathrm{~min}$ in cold PBS, permeabilized in PBS containing $0.1 \%$ Triton $\mathrm{X}-100$ for $10 \mathrm{~min}$ and rinsed again in PBS. Slides were blocked in PBS/5\% Goat serum $15 \mathrm{~min}$ and incubated with primary antibodies in staining buffer $(0.02 \%$ Tween $20,1 \%$ BSA, $1 \%$ goat serum, 5 mM EDTA, pH 7,4) at room temperature for $1 \mathrm{~h}$. Slides were washed 3 times in cold PBS, incubated for $1 \mathrm{~h}$ at $4^{\circ}$ $\mathrm{C}$ with Alexa Fluor 594 or Alexa Fluor $488 \mathrm{~F}$ (ab')2-Goat anti-Mouse IgG $(\mathrm{H}+\mathrm{L})$ or $\mathrm{F}(\mathrm{ab})$ 2-Goat anti-Rabbit IgG $(\mathrm{H}+\mathrm{L})$ (Invitrogen, Burlington, ON). Slides were then washed twice, nucleus were stained with DAPI and visualized with a Leica DM RXA fluorescence upright microscope (Leica, Wetzlar, Germany) and images were processed with Meta Imaging 7.7 software from MetaMorph. For the immunohistochemistry experiment, we used the EnVision+ System-HRP (DAB) kit from DAKO
(Burlington, $\mathrm{ON}$ ) and the protocol was performed according to the manufacturer instructions. Primary antibody anti-calretinin was from Invitrogen, anti-MUC16 and anti-alpha-Smooth muscle actin were from Dako, anti-phospho NF-kB p65 and anti-NF-kB p65 were from Cell Signaling Technology.

\section{CA125 measurements}

CA125 was determined at Centre Hospitalier Universitaire de Sherbrooke laboratory in cell-free culture supernatant samples by EIA using the Roche Modular E170 analyzer and CA125 II regents (Roche Diagnostics, Laval, QC). Values are expressed in kilo Unité Internationale/Liter (kUI/L).

\section{MUC16 transcript levels}

Droplet Digital PCR (ddPCR) reactions for MUC16 are composed of $10 \mu \mathrm{l}$ of $2 \mathrm{X}$ QX200 ddPCR EvaGreen Supermix (Bio-Rad, Hercules, CA), $10 \mathrm{ng}(3 \mu \mathrm{l}) \mathrm{cDNA}$, $100 \mathrm{nM}$ final $(2 \mu \mathrm{l})$ primer pair solutions and $5 \mu \mathrm{lmo}$ lecular grade sterile water (Wisent) for a $20 \mu \mathrm{l}$ total reaction. ddPCR fourplex reactions for reference genes are composed of $10 \mu \mathrm{l}$ of 2X QX200 ddPCR Supermix for probe (Bio-Rad), $10 \mathrm{ng}(3 \mu \mathrm{l}) \mathrm{cDNA}, 250 \mathrm{nM}$ final probe solutions for MRPL19 (FAM, IDT, Coralville, IA) and YWHAZ (HEX, IDT), $125 \mathrm{nM}$ final probe solutions for PUM1 (FAM, IDT) and B2M (HEX, IDT), $0.9 \mu \mathrm{M}$ final primer pair solutions for each reference genes for a $20 \mu \mathrm{l}$ total reaction. Each reaction mix $(20 \mu \mathrm{l})$ was converted to droplets with the QX200 droplet generator (Bio-Rad). Droplet-partitioned samples were then transferred to a 96-well plate, sealed and cycled in a C1000 deep well Thermocycler (Bio-Rad) under the following cycling protocol: $95^{\circ} \mathrm{C}$ for $5 \mathrm{~min}$ (DNA polymerase activation), followed by 50 cycles of $95^{\circ} \mathrm{C}$ for $30 \mathrm{~s}$ (denaturation), 59 ${ }^{\circ} \mathrm{C}$ for $1 \mathrm{~min}$ (annealing) and $72^{\circ} \mathrm{C}$ for $30 \mathrm{~s}$ (extension) followed by post-cycling steps of $4{ }^{\circ} \mathrm{C}$ for $5 \mathrm{~min}$ and $90^{\circ}$ $\mathrm{C}$ for $5 \mathrm{~min}$ (Signal stabilization)) and an infinite $12{ }^{\circ} \mathrm{C}$ hold for MUC16 reactions. Reference gene reactions were cycled under the following cycling protocol: $95^{\circ} \mathrm{C}$ for $5 \mathrm{~min}$ (DNA polymerase activation), followed by 50 cycles of $94{ }^{\circ} \mathrm{C}$ for $30 \mathrm{~s}$ (denaturation), $59^{\circ} \mathrm{C}$ for $1 \mathrm{~min}$ (annealing/extension) followed by post-cycling steps of $98^{\circ} \mathrm{C}$ for $10 \mathrm{~min}$ (enzyme deactivation) and $4{ }^{\circ} \mathrm{C}$ for infinite (Hold). The cycled plate was then transferred and 
read using the QX200 reader (Bio-Rad) either the same or the following day post-cycling. The concentration reported is copies $/ \mu$ of the final $1 \mathrm{x}$ ddPCR reaction (using QuantaSoft software from Bio-Rad) [33].

\section{Conditioned media}

To generate HPMCs-conditioned media, HPMCs were cultured in twelve-well plates in complete medium until they reached $80 \%$ density. Cultured media was removed, cells were washed twice, starved for $4 \mathrm{~h}$ in growth hormone and FBS-free medium and treated overnight in growth hormone free medium containing no FBS, FBS $10 \%$, benign fluid $10 \%$, malignant ascites $0.001-10 \%$, malignant ascites $10 \%$ heat inactivated at $100{ }^{\circ} \mathrm{C}$ for $10 \mathrm{~min}$, TNF-alpha $(20 \mathrm{ng} / \mathrm{ml})$ (New England Biolabs, Whitby, ON), IL-10 (1 ng/ml), IL-6 (2 ng/ml), HGF (1 ng/ml), CCL18 (20 ng/ml), CCL7, CCL8, CCL16, CCL20, CXCL1, IL1-R4 (all at $10 \mathrm{ng} / \mathrm{ml}$ ) (Peprotech, Rocky Hill $\mathrm{NJ})$, Leptin $(0.5 \mathrm{ng} / \mathrm{ml}) \quad(\mathrm{RnD}$ Systems, Minneapolis $\mathrm{MN})$, Actinomycin D (8 nM), NF-kB Inhibitor BAY117082 (Sigma), anti- $\beta 1$ Integrin or anti- $\alpha v \beta 5$ (5 $\mu \mathrm{g} /$ ml) (EMD Millipore, Burlington, MA). When inhibitors or actinomycin D were used, cells were preincubated $1 \mathrm{~h}$ prior the treatment with the inhibitor alone and then treated overnight as described. Cells were washed three times and fresh medium without FBS nor growth factors were added in each well. HPMCs were cultured for 24$96 \mathrm{~h}$ and medium conditioned by stimulated HPMCs were subjected to CA125 quantification. Results were normalized to the total protein concentration in the cell lysate and expressed as kilounits of MUC16 per gram of total proteins.

\section{Western blot analysis}

HPMCs were rinsed twice in PBS, starved for $4 \mathrm{~h}$ in serum and growth hormone free medium and treated overnight in growth hormone free medium containing no FBS, FBS $10 \%$, benign fluid $10 \%$, malignant ascites 10\%, TNF-alpha (20 ng/ml) (New England Biolabs), Actinomycin D (8 nM), NF-kB Inhibitor BAY117082 (Sigma) or AKT Inhibitor 1 L-6-hydroxymethyl-chiro-inositol2($\mathrm{R}$ )-2-O-methyl-3-O-octadecylcarbonate (Sigma). When inhibitors or actinomycin D were used, cells were preincubated $1 \mathrm{~h}$ prior the treatment with the inhibitor alone and then treated overnight as described. Cells were washed with ice-cold PBS and whole cell extracts were prepared in lysing buffer (Glycerol 10\%, Triton X-100 $1 \%$, TRIS $10 \mathrm{mM}$ pH 7.4, NaCl $100 \mathrm{mM}$, EGTA $1 \mathrm{mM}$, EDTA $1 \mathrm{mM}$, SDS $0.1 \%$ ) containing protease inhibitors (0.1 mM AEBSF, $5 \mu \mathrm{g} / \mathrm{ml}$ pepstatin, $0.5 \mu \mathrm{g} / \mathrm{ml}$ leupeptin and $2 \mu \mathrm{g} / \mathrm{ml}$ aprotinin) and phosphatase inhibitors $\left(\mathrm{Na}_{4} \mathrm{P}_{2} \mathrm{O}_{7} 20 \mathrm{mM}\right.$, NaF $\left.1 \mathrm{mM}, \mathrm{Na}_{3} \mathrm{VO}_{4} 2 \mathrm{mM}\right)$. Proteins were separated by $10 \%$ SDS-PAGE gels. Proteins were transferred to PVDF membranes (Roche, Laval, QC) by electroblotting, and immunoblot analysis was performed as previously described (13). All primary antibodies were incubated overnight at $4{ }^{\circ} \mathrm{C}$ in $5 \%$ fat-free milk. Proteins were visualized by enhanced chemiluminescence (GE Healthcare, Baie d'Urfé, QC). Proteins quantification was performed using ImageJ software by National Institutes of Health. Anti-phospho-Akt (Ser483) (\#44-621G), anti-pFAK and anti-pY418 Src antibodies were purchased from Life Technologies (Burlington, ON, Canada). HRP-conjugated anti-mouse (\#7076) and rabbit (\#7074) antibodies, and Akt (\#9272) antibodies were from Cell Signaling Technology. Anti-CA125 M11 antibody was obtained from Dako, anti-GAPDH and anti-Tubulin were from Sigma. Anti-Src was from Thermo Fisher scientific (Burlington, ON, Canada).

\section{Ascites analysis using multiplex cytokine array}

Cytokine levels in peritoneal fluid samples were determined using human cytokine antibody assay ( $G$ series 1000) from RayBiotech Inc. (Norcross, GA). This multiplex assay measures simultaneously 120 different cytokines on a glass chip format. In this method, the levels of cytokines are expressed as relative fluorescent units and can be used to compare cytokine levels in different ascites. This method does not provide the concentration $(\mathrm{pg} / \mathrm{ml})$ of cytokines. The signal intensities were quantified using the ScanArray express dual-color confocal laser scanner (Perkin Elmer). Data were collected in Cy3 channel and stored as paired TiFF images. Spots were identified and local background substracted using the TiGR_Spotfinder 3.1.1 software. By comparing the signal intensities, relative levels of cytokines can be established.

\section{Statistical analysis}

Comparison between unpaired groups was possible using the Mann-Whitney test or the Kruskal-Wallis test. The threshold for statistical significance is $P<0.05$.

\section{Results}

\section{Basal MUC16 expression and secretion in HPMC monolayer cultures}

Constitutive synthesis and shedding of MUC16 glycoprotein have been previously reported in HPMC monolayer cultures suggesting that HPMCs may be an important source of the MUC16 found in the ascites and sera of women with ovarian cancer [24]. We thus determine the basal MUC16 protein expression in primary HPMC monolayer cultures $(n=2)$. Primary HPMCs did not constitutively expressed MUC16 as demonstrated by immunohistochemistry staining (Fig. 1a). However, HPMCs stained strongly for $\alpha$ smooth muscle actin ( $\alpha \mathrm{SMA})$, a myofibroblastic marker, and calretinin, a specific mesothelial marker (Fig. 1a and b). In line with these data, MUC16 expression was not 


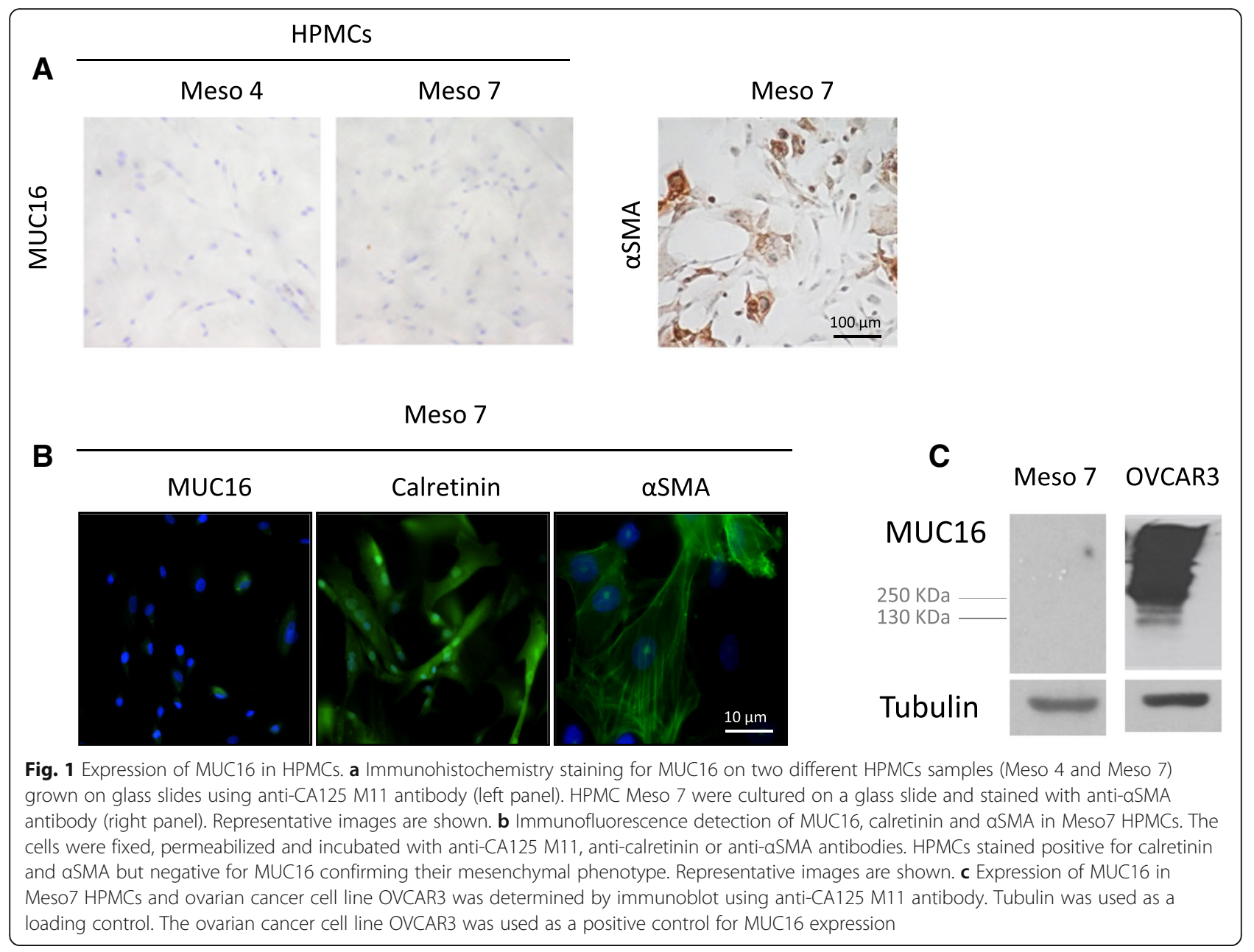

detected by immunofluorescence microscopy (Fig. 1b) or by immunoblot analysis in HPMC cultures (Fig. 1c). The release of MUC16 in HPMCs cultures was barely detectable in the supernatant of HPMC cultures (range 1 to $1.2 \mathrm{kUI} / \mathrm{L})$. These data demonstrate that HPMCs do not show constitutive MUC16 expression and release in primary HPMC monolayer cultures.

\section{Ascites stimulate MUC16 protein expression and secretion in HPMCs}

HGSOC ascites are a pro-inflammatory tumor environment that contains a variety of cytokines, chemokines and growth factors including leptin, hepatocyte growth factor (HGF), IL-6, and CCL18 [30-32, 34]. Through binding to specific cell surface receptors, these factors may activate changes in the expression pattern of molecules essential for ovarian cancer progression. Because pro-inflammatory cytokines have been previously shown to stimulate expression of membrane-bound mucins such as MUC1, MUC4, and MUC16 in tumor cells [2629, 35-37], we hypothesized that ascites could enhance MUC16 expression in HPMCs. We thus determined the effect of different HGSOC ascites $(n=5)$ on MUC16 expression and secretion. The characteristics of these ascites are shown in Table 1. In the absence of ascites, little or no MUC16 expression was detectable by immunoblot (Fig. 2a). In contrast, HGSOC ascites stimulated the expression of MUC16 protein in HPMCs, although the degree of stimulation markedly varied between ascites. TNF $\alpha(25 \mathrm{ng} / \mathrm{ml})$, which has been previously reported to stimulate MUC16 expression in breast and ovarian cancer cells [26], failed to increase MUC16 protein expression in HPMCs (Fig. 2a). Immunofluorescence analysis also demonstrated the stimulation of MUC16 expression by OVC439 and OVC690 ascites in HPMCs (Fig. 2b). In MUC16 overexpressing epithelial ovarian cancer cell lines such as OVCAR3, MUC16 expression distribution is mainly limited to the cell surface (Fig. 2b). In ascites-stimulated HPMCs, MUC16 localization was more diffuse (Fig. 2b). We next measured the release of MUC16 in the conditioned medium of ascites-primed HPMCs (Fig. 2c). There was a robust stimulation of MUC16 secretion (1.5 to 37-fold) in the conditioned medium of HPMC cultures primed with ovarian cancer 


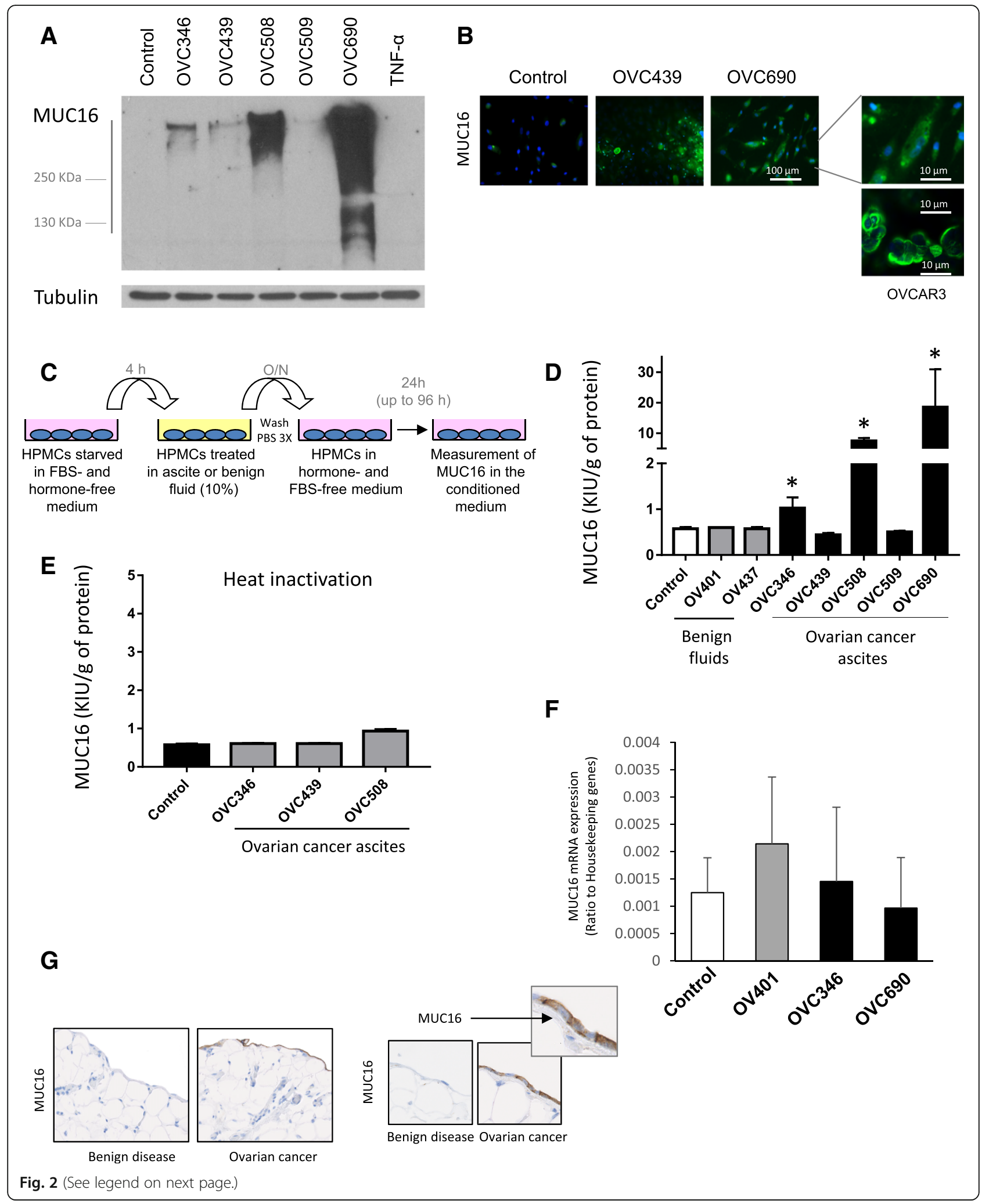

ascites (Fig. 2d). Of note, OVC439 and OVC509 ascites, which had a modest stimulation of MUC16 expression by immunoblot (Fig. 2a), failed to induce a significant increase of MUC16 release relative to the control. Importantly, peritoneal fluids from women with benign conditions $(n=2)$ failed to stimulate the secretion of 
(See figure on previous page.)

Fig. 2 Ovarian cancer ascites stimulates MUC16 expression and release in HPMCs. a Meso7 HPMCs were cultured for $24 \mathrm{~h}$ in the presence of different ascites $(10 \% \mathrm{v} / \mathrm{V})$, TNFa $(25 \mathrm{ng} / \mathrm{ml})$ or FBS 10\% (control). Cell lysates were obtained and immunoblot were performed to assess MUC16 expression. Tubulin was used as a loading control. b Immunofluorescence detection of MUC16 in Meso7 HPMCs. Meso7 cells were primed with OVC439 and OVC690 ascites (10\% v/v) for $24 \mathrm{~h}$ and cells were fixed with 3.7\% formaldahyde, permeabilized with $0.1 \%$ triton and stained with anti-CA125 M11 antibody (left panel). OVCAR3 cells were treated similarly. Magnification of Meso7 treated with OVC690 ascites and OVCAR3 cells stained with anti-CA125 M11 antibody (right panel). c Schematic representation of HPMCs experimental approach for the measurement of MUC16 in conditioned medium. HPMCs were incubated in medium containing 10\% FBS until confluence was reached. Cells were then washed, starved for $4 \mathrm{~h}$, treated with different ascites or benign fluids as indicated and incubated overnight. Cells were then washed 3 times and incubated in serum-free medium for an additional $24 \mathrm{~h}$ or more. The conditioned medium was collected, centrifuged and the supernatants were assessed for MUC16 detection. $\mathbf{d}$ Levels of MUC16 in the supernatant of conditioned medium of treated Meso7. Levels were standardized according to the total protein concentration. Results are from two independent experiments performed in duplicates. ${ }^{*}$ indicates $P<0.001$. e Ascites were heat-inactivated by heating at $100^{\circ} \mathrm{C}$ for $10 \mathrm{~min}$ followed by centrifugation at $13,000 \mathrm{rpm}$ for $15 \mathrm{~min}$. HPMCs were incubated with inactivated ascites or medium containing 10\% FBS (control). Results are from two independent experiments performed in duplicates. f Meso7 cells were starved in medium without FBS nor hormones for $4 \mathrm{~h}$ and then incubated 4 or $8 \mathrm{~h}$ with medium containing either $10 \%$ FBS (control), $10 \%$ benign fluid OV401 or 10\% ascites (OVC346, OVC690). MUC16 mRNA levels were quantified by ddPCR. MUC16 concentration data from ddPCR experiments are expressed as ratio against reference genes for each sample. $P>0.05$. Results are from a single experiment performed in triplicates. $\mathbf{g}$ Immunohistochemistry of MUC16 on human omentum section, in benign disease versus ovarian cancer conditions (Picture taken at 10X magnification, left panel). The counterstaining was done with haematoxylin to allow nuclei visualization. Representative images from omental biopsies from two ovarian cancer and one patient with a benign disease were obtained and multiple section were analyzed. Enlarged representative images (40X magnification; right panel) shows the localisation of MUC16 at the mesothelium in ovarian cancer omentum

MUC16 in HPMCs suggesting that the ascites factors responsible for the stimulation of MUC16 release may be absent or present at a lower concentration in benign peritoneal fluids. Heat-inactivation of ovarian cancer ascites almost completely abrogated their ability to stimulate MUC16 secretion suggesting that the MUC16-stimulating factor(s) in ascites are most likely proteins (Fig. 2e). Next, we determined MUC16 mRNA levels in response to benign fluid OV401 and malignant ascites OVC346 and OVC690. Fluids were added at a concentration of $10 \%(\mathrm{v} / \mathrm{v})$ and cells were treated for 4 or $8 \mathrm{~h}$. MUC16 mRNA expression was not stimulated by the presence of HGSOC ascites (Fig. 2f). Indeed,
MUC16 mRNA levels were not significantly different in ascites-treated HPMCs versus cells incubated with serum (control) or benign fluid OV401. These data suggest that most HGSOC ascites consistently stimulate the protein expression and release of MUC16 in HPMC cultures without affecting MUC16 mRNA levels. To examine the clinical relevance of these in vitro findings, we stained omental biopsies from patients with non-inflammatory conditions and omental biopsies from patients with HGSOC for MUC16 expression. As shown in Fig. 2g, MUC16 expression was only detectable on the mesothelium lining of omental biopsies from patients with HGSOC.
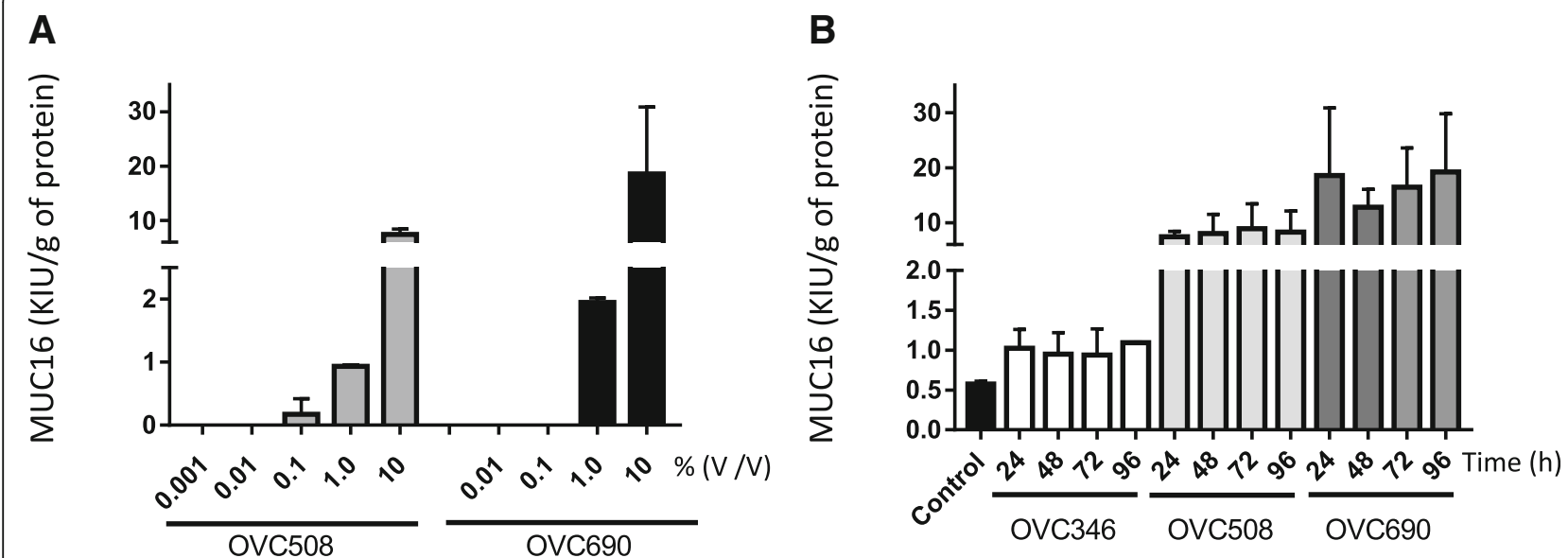

Fig. 3 Dose-dependent release of MUC16 in HPMCs treated with ascites (0,001-10\%). a Meso7 cells were incubated with increasing concentrations of OVC508 or OVC690 ascites overnight, cells were rinsed 3 times and MUC16 shedding was determined in the conditioned medium $24 \mathrm{~h}$ later. b Meso7 cells were incubated overnight with ascites $(10 \% \mathrm{~V} / \mathrm{V})$, rinsed 3 times and MUC16 shedding was determined after 24 $\mathrm{h}$ and up to $96 \mathrm{~h}$ post treatment. Levels were standardized according to the total protein concentration. Results are from two independent experiments performed in duplicates 


\section{Ascites stimulate MUC16 secretion in HPMCs in a dose- dependent manner}

Next, we determined the dose responsiveness of MUC16 secretion to ovarian cancer ascites (Fig. 3a). Ovarian cancer ascites OVC508 and OVC690 were selected because of their strong MUC16-stimulating effect. Ascites were added at concentrations ranging from 0.01 to $10 \%$ $v / \mathrm{v}$ to HPMC cultures and the release of MUC16 in the supernatant was measured. In these experiments, OVC508 and OVC690 ascites concentration as low as $1 \%$ resulted in a significant stimulation of MUC16 release. At $10 \%$ concentration, each ascites induced a very robust stimulation of MUC16 release ( $>18$ and $>44$-fold respectively). Maximal stimulation of MUC16 release was reached within $24 \mathrm{~h}$ following exposure to ascites. Longer exposure to ascites did not significantly increased MUC16 release in the supernatant of HPMC cultures (Fig. 3b).

\section{Akt activation but not NF-KB is involved in ascites- induced MUC16 expression}

MUC16 expression has been shown to be NF- $\kappa B$-dependent in some cancer cell lines $[26,38]$. Because we had evidence that NF-kB-mediated transcription is stimulated by ascites in ovarian cancer cell lines (Lane, unpublished data), and because NF- $\mathrm{kB}$ is a downstream effector of several cytokines, we assessed the role of NF- $\mathrm{kB}$ in ascites-induced stimulation of MUC16 expression and release. To this end, we assessed, by immunohistochemistry, the nuclear localization of $N F-k B$ family member RelA (p65), which is phosphorylated and accumulates in the nucleus when the NF- $\mathrm{BB}$ pathway is activated. As shown in Fig. 4a, TNF $\alpha$, a well-known NF- $\mathrm{kB}$ activator, induced the phosphorylation and accumulation of p65 in the nucleus of HPMC cultures. In contrast, incubation of HPMC cultures with ovarian cancer ascites displayed p65 nuclear accumulation that were similar to the control suggesting that ascites do not stimulate NF- $\mathrm{kB}$ activity in HPMCs. As c-Src is an upstream activator of NF- $\mathrm{kB}$ pathway, we assessed whether ascites could activate c-Src. As shown in Fig. 4b, ascites failed to induce c-Src which is consistent with data from Fig. 4a. In line with these data, NF- $\mathrm{B}$ inhibitor BAY117082 had no effect on ascites-induced MUC16 protein expression (Fig. 4b) and release (Fig. 4c). Collectively, these data demonstrate that ascites-induced MUC16 expression and release is independent of NF-kB activation.

Ovarian cancer ascites induces Akt activation in ovarian cancer cells $[39,40]$. Hence, we speculated that ascites-mediated increased MUC16 expression in HPMC monolayer cultures might be dependent on Akt activation. To test this hypothesis, we assessed Akt activation in HPMCs incubated with ovarian cancer ascites $(n=3)$.
As shown in Fig. 5a, ascites induced Akt activation as compared to benign fluid (OV401) or control by at least a 2-fold. Heat inactivation drastically reduced OVC346 ascites-induced Akt activation (Fig. 5b). In line with data from Fig. 3a, we observed a dose-dependent phosphorylation of Akt with increasing concentration of ascites (Fig. 5c) indicating that ovarian cancer ascites stimulate Akt activation in HPMCs. To confirm the hypothesis that ascites-stimulated MUC16 expression and release is mediated through an Akt-dependent pathway, we examined the ability of the Akt1/2 specific inhibitor, 1 L-6-hydroxymethyl-chiro-inositol 2(R)-2-O-methy1-3-O-octadecylcarbonate, to inhibit ascites-enhanced MUC16 expression and ectodomain release. Akt inhibition decreased ascites-induced MUC16 protein expression by at least 2-fold (Fig. 5e) and significantly inhibited $(\sim 30 \%) \quad$ MUC16 shedding, suggesting that ascites-mediated MUC16 expression and shedding involve, at least partially, an Akt-dependent signaling pathway. As expected, Akt inhibition had no effect on the level of MUC16 mRNA expression (Fig. 5f).

Because we have previously shown that ascites-induced Akt activation in ovarian cancer cells is mediated by $\alpha v \beta 5$ integrin and focal adhesion kinase (FAK) activation [40], we determined whether ascites that strongly promote MUC16 expression and secretion could induce FAK activation in HPMCs. As shown in Fig. 5g, OVC346 and OVC690 ascites failed to enhance FAK phosphorylation and its downstream target c-Src in HPMCs. Consistent with these findings, the addition of blocking antibodies anti- $\beta 1$ and anti- $\beta 5$ had no effect on OVC508 ascites-induced MUC16 release (Fig. 5h) thus confirming that ascites-induced Akt activation in HMPCs is not mediated through an integrin/FAK pathway.

\section{Ascites factor(s) associated with MUC16 release}

The lack of stimulation of MUC16 release by benign peritoneal fluids (Fig. 2d) suggest that factors differentially expressed between ovarian cancer ascites and benign peritoneal fluids could be responsible for ascites-induced stimulation of MUC16 expression and release. To identify inflammation-related factors in ascites that might be responsible for stimulating MUC16 release, we performed a cytokine array on ascites samples. Among the 120 cytokines tested, the top ten differentially expressed between MUC16-stimulating and none-stimulating fluids were IL-6, CXCL1, CCL20, hepatocyte growth factor (HGF), IL-16, IL-1R4, CCL7, CCL8, CCL16 and IL-10 (Table 2). None-stimulating peritoneal fluids were defined as those with less then two-fold MUC16 release increased in conditioned medium relative to the control, which included OV401, OV437, OVC439 and OVC509 fluids. Incubation of 


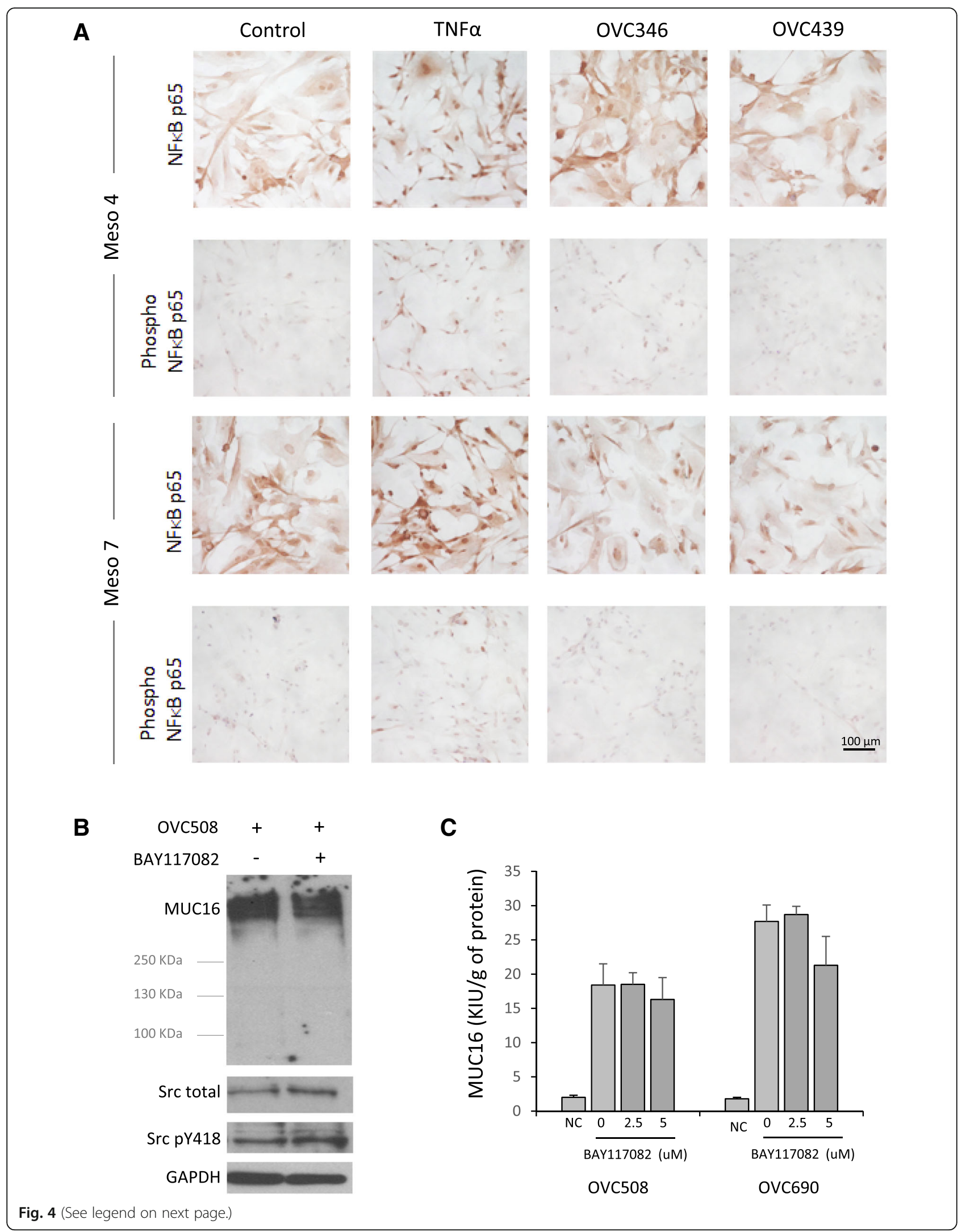


(See figure on previous page.)

Fig. 4 NF-KB activation in HPMCs. a Total and phosphorylated NF-KB p65 expression and localization were determined in two HPMCs samples (Meso 4 and Meso 7 cells) using anti-NF-kB p65 specific antibodies. HPMCs were incubated with either FBS (10\%), TNF-a (20 ng/ml), OVC346 (10\%) or OVC439 (10\%) for 20 min. b Meso7 cells were incubated with OVC508 ascites (10\% v/v) in the presence or absence of NFKB inhibitor BAY117082 $(5 \mu \mathrm{M})$ for $24 \mathrm{~h}$. Cells were then washed three times with PBS and incubated with standard medium for $24 \mathrm{~h}$. Lysates were then obtained and immunoblotted for MUC16, c-Src and phosphorylated (Y418) c-Src. GAPDH was used as a loading control. c Meso 7 cells were pretreated or not with BAY117082 (2 or $5 \mu \mathrm{M})$ for $1 \mathrm{~h}$ prior to the addition of ascites OVC508 or OVC690 (10\%) to the medium. Cells were incubated overnight. The next day, cells were washed 3 times and incubated $24 \mathrm{~h}$ with standard medium. The medium was removed and MUC16 concentration were measured in the condition medium. Results are from two independent experiments performed in duplicates

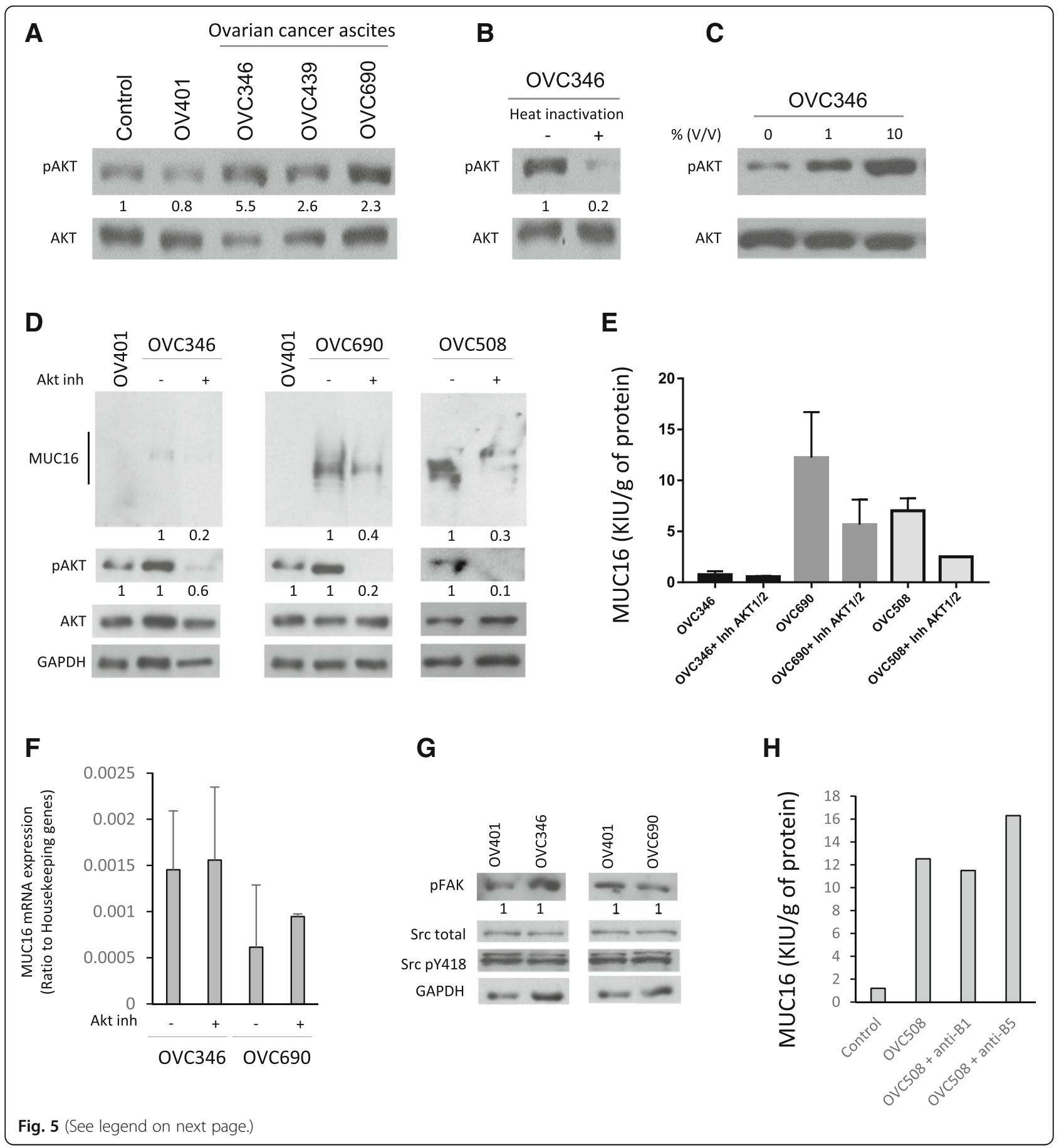


(See figure on previous page.)

Fig. 5 Ovarian cancer ascites stimulate MUC16 expression and release through Akt. a Meso 7 cells were incubated with FBS 10\% (control), OV401 $10 \%$ or 3 different ovarian cancer ascites at 10\%. The expression of Akt and phosphorylated Akt were determined by immunoblot using anti-Akt and anti-phospho-Akt antibodies. Representative images from two independent experiments. Densitometric quantification of phosphorylated Akt normalized to total Akt is represented between the two blots. b OVC346 ascites was heat-inactivated by heating at $100^{\circ} \mathrm{C}$ for 10 min followed by centrifugation at 13,000 rpm for 15 min. Meso7 cells were incubated with OVC346 (10\%) or heat-inactivated OVC346 ascites (10\%). Akt and phosphorylated Akt expression were assessed by immunoblot after $24 \mathrm{~h}$. Expression of phosphorylated Akt was normalized to total Akt and densitometric quantification is shown between the blots. Representative images from two independent experiments. c Meso 7 cells were incubated with increasing concentrations of OVC346 ascites (0 to 10\% v/v) and Akt and phosphorylated Akt expression were determined by immunoblot. d Meso7 cells were incubated with OV401 (10\%) or ovarian cancer ascites (10\%) in the presence or absence of Akt1/2 inhibitor ( 5 MM). MUC16, Akt and phosphorylated Akt expression were determined by immunoblot. Representative images from two independent experiments. Expression of phosphorylated Akt was normalized to total Akt and MUC16 expression was normalized to housekeeping gene GAPDH. e MUC16 release was measured in supernatants of Meso7 cells incubated with three different ovarian cancer ascites in the presence or absence of Akt1/2 inhibitor ( $5 \mu \mathrm{M})$. Bars represent standard deviation from two independent experiments conducted in duplicates. $\mathbf{f}$ Meso7 cells were incubated with OVC346 or OVC690 (10\%) in the presence or absence of Akt1/2 inhibitor. MUC16 mRNA levels were quantified by ddPCR. MUC16 concentration data from ddPCR experiments are expressed as ratio against reference genes for each sample. Results are from two independent experiments conducted in duplicates. $\mathbf{g}$ Meso7 cells were incubated with benign fluid OV401 or ovarian cancer ascites OVC346 or OVC690 (10\%). Expression of phosphorylated FAK, phosphorylated and total c-Src was determined by immunoblot. Representative images from two independent experiments. Densitometric quantification of phosphorylated FAK normalized to GAPDH is shown between the blots. $\mathbf{h}$ Cells were incubated with $\beta 1$ or $\beta 5$ integrin-blocking antibodies $(5 \mu \mathrm{g} / \mathrm{ml}$ ) for 30 min before adding $10 \%$ OVC508 ascites overnight. Cells were then washed 3 times and fresh FBS and hormone-free medium was added. MUC16 release was then measured in supernatants after $24 \mathrm{~h}$. Data are from a single experiment

HPMC monolayer cultures with recombinant IL-6, HGF, CCL7, CCL8, CCL16, CCL20, CXCL1 and IL-10 at biologically relevant concentrations failed to stimulate MUC16 protein expression or its release in the supernatant of HPMC cultures (Table 3). Furthermore, incubation of HPMCs with recombinant CCL18 and Leptin, two molecules previously shown to alter HPMC signaling [41, 42], had no effect on MUC16 expression and release (Table 3). In line with these data, antibody-mediated inhibition of IL-6 and HGF did not altered MUC16 release (data not shown).

\section{Discussion}

Despite the fact that the measurement of MUC16 extracellular domain (CA125) in the sera has been the mainstay of HGSOC assessment and management since the early 1980's, there are considerable gaps in our knowledge regarding the regulation of MUC16 expression and release in the context of ovarian cancer. Given the immunoprotective role of MUC16 ectodomain, identifying how the tumor environment alters MUC16 expression and secretion in cancer-associated stromal cells may provide a new way to block immune evasion by tumors. In the present study, we demonstrate for the first time that HGSOC ascites, a highly inflammatory tumor environment, markedly up-regulates the expression of MUC16 glycoprotein in primary HPMCs and stimulate its release from the cell surface. The regulation of ascites-mediated upregulation of MUC16 expression occurs at the post-transcriptional level. Furthermore, we show that ascites-induced stimulation of MUC16 expression is largely mediated by the activation of Akt pathway in HPMCs. Although we identified a number of cytokines, chemokines and growth factors preferentially

Table 2 Top ten factors differentially expressed between MUC16-stimulating and non-stimulating ascites $(P<0.05)$

\begin{tabular}{llllc}
\hline Factors & $\begin{array}{l}\text { MUC16-nonstimulating Mean }{ }^{\mathrm{a}}( \pm \text { SEM) } \\
(n=5)\end{array}$ & $\begin{array}{l}\text { MUC16-stimulating Mean }( \pm \text { SEM }) \\
(n=2)\end{array}$ & Fold increased \\
\hline IL-6 & $2545( \pm 399)$ & $24,357( \pm 802)$ & 9.6 & $<0.0001$ \\
CXCL1 & $3736( \pm 247)$ & $26,265( \pm 4506)$ & 7.0 & 0.9 \\
CCL20 & $656( \pm 31)$ & $4525( \pm 666)$ & 4.6 & $<002$ \\
HGF & $2321( \pm 450)$ & $10,561( \pm 1069)$ & 4.2 & 0.0001 \\
IL-16 & $788( \pm 71)$ & $3344( \pm 675)$ & 4.2 & 0.0001 \\
IL-1 R4 & $948( \pm 59)$ & $3957( \pm 850)$ & 4.0 & 0.0021 \\
CCL7 & $571( \pm 23)$ & $2276( \pm 322)$ & 3.5 & 0.0033 \\
CCL8 & $548( \pm 23)$ & $1901( \pm 276)$ & 3.4 & 0.0001 \\
CCL16 & $1152( \pm 166)$ & $3886( \pm 627)$ & 3.3 & 0.0009 \\
IL-10 & $2328( \pm 713)$ & $7701( \pm 1144)$ & 0.0014 \\
\hline
\end{tabular}

${ }^{a}$ Means are expressed in relative fluorescence units 
Table 3 Effect of selected soluble factors on MUC16 release in HPMCS

\begin{tabular}{lll}
\hline Factors & Concentrations & Stimulation of MUC16 release \\
\hline IL-6 & $2 \mathrm{ng} / \mathrm{ml}$ & No \\
IL-10 & $1 \mathrm{ng} / \mathrm{ml}$ & No \\
TNFa & $25 \mathrm{ng} / \mathrm{ml}$ & No \\
Leptin & $500 \mathrm{pg} / \mathrm{ml}$ & No \\
HGF & $1 \mathrm{ng} / \mathrm{ml}$ & No \\
CCL7 & $10 \mathrm{ng} / \mathrm{ml}$ & No \\
CCL8 & $10 \mathrm{ng} / \mathrm{ml}$ & No \\
CCL16 & $10 \mathrm{ng} / \mathrm{ml}$ & No \\
CCL20 & $10 \mathrm{ng} / \mathrm{ml}$ & No \\
CXCL1 & $10 \mathrm{ng} / \mathrm{ml}$ & No \\
\hline
\end{tabular}

expressed in MUC16-stimulating ascites versus those without stimulating effects, we were unable to demonstrate that any of these factors were responsible for ascites-induced MUC16 expression in HPMCs.

MUC16 may be expressed by various tumor cell types and by some normal epithelial cells. Expression of MUC16 has been reported in ocular surface epithelial cells lines [29, 43, 44] and tracheal surface epithelium [45]. Although cytokines may be involved in MUC16 shedding by ocular cells, the regulation of MUC16 shedding by cytokines appears to be complex. For example, whereas IL- $1 \alpha$, IL- $1 \beta$ and TNF $\alpha$ failed to increase MUC16 mRNA levels in human corneal cells, treatment with these cytokines was nonetheless associated with increased MUC16 shedding [28]. In contrast, treatment of human conjunctival cells with IL- $1 \alpha$, IL- $1 \beta$ and TNF $\alpha$ reduced MUC16 shedding despite increasing MUC16 mRNA levels. The data suggest that cytokines may produce several patterns of MUC16 regulation in normal epithelial cells in which the amount of MUC16 in cells and the amount of MUC16 shedding do not always correlate. Therefore, depending on the cellular context, MUC16 shedding may be increased without changes in mucin mRNA levels. Our data show that there is good correlation between MUC16 protein levels and ectodomain release suggesting that MUC16 is upregulated suggesting that ascites regulates MUC16 expression at a post-transcriptional level.

The stimulation of MUC16 release by cytokines in various cancer cell lines, including, endometrial, breast and ovarian tumor cells have also been variable. TNF $\alpha$ and IFNy, the two most studied cytokines in that context, have been shown to enhance MUC16 shedding in some but not all cancer cell lines suggesting also a complex regulation of MUC16 expression that is dependent on the cellular context. NF- $\mathrm{kB}$ has been involved in cytokine-mediated stimulation of MUC16 release in cancer cells [26]. In contrast to this finding, we show here that TNF $\alpha$ does not affect MUC16 expression and release in HPMCs. Furthermore, we demonstrated that although NF- $\mathrm{BB}$ may be activated by ascites in OC cells, this pathway is not involved in ascites-mediated MUC16 stimulation in HPMCs as demonstrated by the lack of ascites-mediated NF- $\mathrm{kB}$ p 65 phosphorylation and the lack of effect of NF-kB specific inhibitor BAY117082 on MUC16 expression. Based on these observations, it appears that although both tumor and mesothelial cells may produce MUC16 under inflammatory conditions; the mechanisms regulating MUC16 expression differ between these cells.

In this study, we show that MUC16 expression is, at least partly, regulated by Akt activation as demonstrated by the observation that ascites induce Akt activation in a dose-dependent manner and the fact that a specific Akt inhibitor strongly reduced MUC16 expression and release. The mechanism by which Akt stimulate MUC16 expression and release remains unclear. Serum CA125 correlates with progression and regression of the disease and this formed the basis for monitoring CA125 serum levels for patient follow-up [7, 8]. However, the fact that mesothelial cells are a major source of secreted CA125 in a pro-inflammatory surrounding environment such as ascites would suggest that rising and falling CA125 levels merely reflect the degree of inflammation in a patient rather than the tumor burden itself.

\section{Conclusions}

In summary, our data reveal that peritoneal mesothelial cells may be an important source of MUC16 when exposed to HGSOC ascites, but the regulation of MUC16 expression appears to be complex. In addition, although ascites regulate MUC16 expression at a posttranscriptional level through an Akt-dependent pathway, the ascites factors involved in MUC16 expression upregulation remains to be characterized.

\section{Abbreviations}

CA125: Cancer antigen 125; CCL: Chemokine (C-C motif) ligand; CTD: Cterminal domain; CTRNet: Canadian Tumor Repository Network; CXCL: Chemokine (C-X-C motif) ligand; ddPCR: droplet Digital PCR; FAK: Focal adhesion kinase; FIGO: International Federation of Gynecology and Obstetrics; HGF: Hepatocyte growth factor; HGSOC: High grade serous ovarian cancer; HPMCs: Human peritoneal mesothelial cells; IFN: Interferon; IL: Interleukin; MMP: Metalloprotease; NE: Neutrophil elastase; NF-kB: Nuclear factor KB; NK: Natural killer; OC: Ovarian cancer; TNF: Tumor necrosis factor

\section{Acknowledgements}

We wish to thank the Banque de tissus et de données du Réseau de Recherche en Cancer du Fond de Recherche du Québec en Santé (FRQS), affiliated to the Canadian Tumor Repository Network (CTRNet) for providing the ascites samples.

\section{Funding}

This work was supported by a grant from the "Programme d'aide de financement interne" of the Centre de Recherche du Centre Hospitalier Universitaire de Sherbrooke and Université de Sherbrooke. The funder had 
no participation in the design of the study and collection, analysis, and interpretation of data nor in writing the manuscript.

\section{Availability of data and materials}

The datasets generated during and/or analysed during the current study are available from the corresponding author on reasonable request.

\section{Author's contributions}

IM participated in the design of the study and performed all assays. IM was also responsible for obtaining the ascites and the clinical data. Pathological specimens were reviewed by PGG. PB provided the clinical specimen for the banking. AP conceived the study, participated in its design and drafted the manuscript. All authors read and approved the final version of this manuscript.

\section{Ethics approval and consent to participate}

This study was approved by our Institutional Review Board named «Comité d'éthique de la recherche du CIUSSS de l'Estrie - CHUS». Informed written consent was obtained from women that underwent surgery by the gynecologic oncology service between 2000 and 2017. The committee reference number of this project is \#1999-11, 98-51.

\section{Consent for publication}

Not applicable.

\section{Competing interests}

The authors declare that they have no competing interests.

\section{Publisher's Note}

Springer Nature remains neutral with regard to jurisdictional claims in published maps and institutional affiliations.

\section{Author details}

'Département de Microbiologie et Infectiologie, Université de Sherbrooke, 3001, 12ième Avenue Nord, Sherbrooke, Québec J1H 5N4, Canada. ²Département de Pathologie, Faculté de Médecine, Université de Sherbrooke, 3001, 12ième Avenue Nord, Sherbrooke J1H 5N4, Canada. ${ }^{3}$ Département de Chirurgie, service de gynécologie-obstétrique, Faculté de Médecine, Université de Sherbrooke, 3001, 12ième Avenue Nord, Sherbrooke $\mathrm{J} 1 \mathrm{H}$ 5N4, Canada.

Received: 18 April 2018 Accepted: 12 April 2019

Published online: 30 April 2019

\section{References}

1. Piché A. Pathobiological role of MUC16 mucin (CA125) of ovarian cancer: much more than a tumor biomarker. World J Obstet Gynecol. 2016;5:39-49.

2. Yin BW, Lloyd KO. Molecular cloning of the CA125 ovarian cancer antigen: identification as a new mucin, MUC16. J Biol Chem. 2001;276:27371-5.

3. Yin BW, Dnistrian A, Lloyd KO. Ovarian cancer antigen CA125 is encoded by the MUC16 mucin gene. Int J Cancer. 2002;98:737-40.

4. O'Brien TJ, Beard JB, Underwood LJ, Shigemasa K. The CA125 gene: a newly discovered extension of the glycosylated $\mathrm{N}$-terminal domain doubles the size of this extracellular superstructure. Tumour Biol. 2002;23:154-69.

5. O'Brien TJ, Beard JB, Underwood LJ, Dennis RA, Santin AD, York L. The CA125 gene: an extracellular superstructure dominated by repeat sequences. Tumor Biol. 2001;22:348-66.

6. Canney PA, Moore M, Wilkinson PM, James RD. Ovarian cancer antigen CA125: a prospective clinical assessment of its role as a tumour marker. $\mathrm{Br} J$ Cancer. 1984;50:765-9.

7. Vergote IB, Børmer OP, Abeler VM. Evaluation of serum CA 125 levels in the monitoring of ovarian cancer. Am J Obstet Gynecol. 1987;157:88-92.

8. Bast RC Jr, Klug TL, St-John E, Jenison E, Niloff JM, Lazarus H, Berkowitz RS, Leavitt T, Griffiths CT, Parker L, Zurawski VR Jr, Knapp RC. A radioimmunoassay using a monoclonal antibody to monitor the course of epithelial ovarian cancer. New Eng J Med. 1983;309:883-7.

9. Blalock TD, Spurr-Michaud SJ, Tisdale AS, Gipson IK. Release of membraneassociated mucins from ocular surface epithelia. Invest Ophthalmol Vis Sci. 2008:49:1864-71.

10. Govindarajan B, Menon BB, Spurr-Michaud S, Rastogi K, Gilmore MS, Argueso P, Gipson IK. A metalloproteinase secreted by Streptococcus pneumonia removes membrane mucin MUC16 from the epithelial glycocalyx barrier. PLoS One. 2012;73:e32418.

11. Das S, Majhi PD, Al-Mugotir MH, Rachagani S, Sorgen P, Batra SK. Membrane proximal ectodomain cleavage of MUC16 occurs in the acidifying Golgi/ post-Golgi compartments. Sci Rep. 2015;5:9759.

12. Kufe DW. Mucins in cancer: function, prognosis and therapy. Nat Rev Cancer. 2009;9:874-85.

13. Thériault C, Pinard M, Comamala M, Migneault M, Beaudin J, Matte I, Boivin M, Piché A, Rancourt C. MUC16 (CA125) regulates epithelial ovarian cancer cell growth, tumorigenesis and metastasis. Gynecol Oncol. 2011;121:434-43.

14. Giannakouros P, Matte I, Rancourt C, Piché A. Transformation of NIH3T3 mouse fibroblast cells by MUC16 mucin (CA125) is driven by its cytoplasmic tail. Int J Oncol. 2015:46:91-8.

15. Akita K, Tanaka M, Tanida S, Mori Y, Toda M, Nakada H. CA125/MUC16 interacts with Src family kinases, and over-expression of its C-terminal fragment in human epithelial cancer cells reduces cell-cell adhesion. Eur J Cell Biol. 2013;92:257-63.

16. Reinartz S, Failer S, Schuell T, Wagner U. CA125 (MUC16) gene silencing suppresses growth properties of ovarian and breast cancer cells. Eur J Cancer. 2012;48:1558-69.

17. Das S, Rachagani S, Torres-Gonzalez MP, Lakshmanan I, Majhi PD, Smith LM, Wagner KU, Batra SK. Carboxyl-terminal domain of MUC16 imparts tumorigenic and metastatic functions through nuclear translocation of JAK2 to pancreatic cancer cells. Oncotarget. 2015;6:5772-87.

18. Lakshmanan I, Ponnusamy MP, Das S, Chakraborty D, Haridas D, Mukhopadhyay P, Lele SM, Batra SK. MUC16 induced rapid G2/M transition via interactions with JAK2 for increased proliferation and anti-apoptosis in breast cancer cells. Oncogene. 2012;31:805-17.

19. Boivin M, Lane D, Piché A, Rancourt C. CA125 (MUC16) tumor antigen selectively modulates the sensitivity of ovarian cancer cells to genotoxic drug-induced apoptosis. Gynecol Oncol. 2009;115:407-13.

20. Matte I, Lane D, Boivin M, Rancourt C, Piché A. MUC16 mucin (CA125) attenuates TRAIL-induced apoptosis by decreasing TRAIL R2 expression and increasing c-FLIP expression. BMC Cancer. 2014;14:234.

21. Felder M, Kapur A, Gonzalez-Bosquet J, Horibata S, Heintz J, Albrecht R, Fass L, Kaur J, Hu K, Shojaei H, Whelan RJ, Patankar MS. MUC16 (CA125): tumor biomarker to cancer therapy, a work in progress. Mol Cancer. 2014;13:129.

22. Kabawat SE, Bast RC Jr, Bhan AK, Welch WR, Knapp RC, Colvin RB. Tissue distribution of a coelomic-epithelium-related antigen recognized by the monoclonal antibody OC125. Int J Gynecol Pathol. 1983;2:275-85.

23. Nap M. Immunohistochemistry of CA125. Unusual expression in normal tissues, distribution in the human fetus and questions around its application in diagnostic pathology. Int J Biol Markers. 1998;13:210-5.

24. Zeimet AG, Marth C, Offner FA, Obrist $P$, Uhl-Steidl M, Feichtinger $H$ Stadlmann S, Daxenbichler G, Dapunt O. Human peritoneal mesothelial cells are more potent than ovarian cancer cells in producing tumor marker CA125. Gynecol Oncol. 1996:62:384-9.

25. Cheema H, Bargman JM. Cancer antigen 125 as a biomarker in peritoneal dialysis: mesothelial cell health or death? Perit Dial Int. 2013;33:349-52.

26. Morgado M, Sutton MN, Simmons M, Warren CR, Lu Z, Constantinou PE, Liu J, Francis LL, Conlan RS, Bast RC, Carson DD. Tumor necrosis factor-a and interferon- $\gamma$ stimulate MUC16 (CA125) expression in breast, endometrial and ovarian cancers through NFKB. Oncotarget. 2016;12:14871-84.

27. Thathiah A, Brayman M, Dharmaraj N, Julian JJ, Lagow EL, Carson DD. Tumor necrosis factor a stimulates MUC1 synthesis and ectodomain release in a human uterine epithelial cell lines. Endocrinology. 2004;145: 4192-203.

28. Albertsmeyer AC, Kakkassery V, Spurr-Michaud S, Beeks O, Gipson IK. Effect of pro-inflammatory mediators on membrane-associated mucins expressed by human ocular surface epithelial cells. Exp Eye Res. 2010;90:444-51.

29. Paulsen $F$, Jäger K, Worlitzsch D, Bräuer L, Schulze U, Schäfer G, Sel S. Regulation of MUC16 by inflammatory mediators in ocular surface epithelial cell lines. Ann Anat. 2008;190:59-70.

30. Matte I, Lane D, Laplante C, Rancourt C, Piché A. Profiling of cytokines in human epithelial ovarian cancer ascites. Am J Cancer Res. 2012;2:566-80.

31. Lane D, Matte I, Garde-Granger P, Laplante C, Carignan A, Rancourt C, Piché A. Inflammation-regulating factors in ascites as predictive biomarkers of drug resistance and progression-free survival in serous epithelial ovarian cancers. BMC Cancer. 2015;15:492.

32. Giuntoli RL, Webb TJ, Zoso A, Rogers O, Diaz-Montes TP, Bristow RE, Oelke M. Ovarian cancer-associated ascites demonstrates altered immune 
environment: implications for antitumor immunity. Anticancer Res. 2009;29: 2875-84.

33. Taylor SC, Carbonneau J, Shelton DN, Boivin G. Optimization of Droplet Digital PCR from RNA and DNA extracts with direct comparison to RT-QPCR: Clinical implications for quantification of Oseltamivir-resistant subpopulations. J Virol Methods. 2015;224:58-66.

34. Matte I, Lane D, Laplante C, Garde-Granger P, Rancourt C, Piché A. Ovarian cancer ascites enhance the migration of patient-derived peritoneal mesothelial cells via cMet pathway through HGF-dependent and independent mechanisms. Int J Cancer. 2015;137:289-98.

35. Chapela PJ, Broaddus RR, Hawkins SM, Lessey BA, Carson DD. Cytokine stimulation of MUC4 expression in human female reproductive tissue carcinoma cell lines and endometrial cancer. J Cell Biochem. 2015;116:264957.

36. Kunigal S, Ponnusamy MP, Momi N, Batra SK, Chellappan SP. Nicotine, IFN- $y$ and retinoic acid mediated induction of MUC4 in pancreatic cancer requires E2F1 and STAT-1 transcription factors and utilize different signaling cascades. Mol Cancer. 2012;11:24

37. Mejias Luque R, Peiro S, Vincent A, Van Seuningen I, de Bolos C. IL-6 induces MUC4 expression through gp130/STAT3 pathway in gastric cancer cell lines. Biochim Biophys Acta. 2008;1783:1728-36.

38. Morgado M, Carson DD. PPARy modulation of cytokine-stimulated MUC16 (CA125) expression in breast and ovarian cancer-derived cells. J Cell Biochem. 2017;118:163-71.

39. Lane D, Robert V, Grondin R, Rancourt C, Piché A. Malignant ascites protect against TRAIL-induced apoptosis by activating the PI3K/Akt pathway in human ovarian carcinoma cells. Int J Cancer. 2007;121:1227-37.

40. Lane D, Goncharenko-Khaider N, Rancourt C, Piché A. Ovarian cancer ascites protects from TRAlL-induced cell death through av $\beta 5$ integrin-mediated focal adhesion kinase and Akt activation. Oncogene. 2010;29:3519-31.

41. Yang AH, Huang SW, Chen JY, Lin JK, Chen CY. Leptin augments myofibroblastic conversion and fibrogenic activity of human peritoneal mesothelial cells: a functional implication for peritoneal fibrosis. Nephrol Dial Transplant. 2007;22:756-62.

42. Lane D, Matte I, Laplante C, Garde-Granger P, Carignan A, Bessette P, Rancourt C, Piché A. CCL18 from ascites promotes ovarian cancer cell migration through proline-rich tyrosine kinase 2 signaling. Mol Cancer. 2016; 15:58

43. Dogru M, Matsumoto Y, Okada N, Igarashi A, Fukagawa K, Shimazaki Tsubota K, Fujishima H. Alterations of the ocular surface epithelial MUC16 and goblet cell MUC5AC in patients with atopic keratoconjunctivitis. Allergy. 2008;63:1324-34

44. Argüeso P, Spurr-Michaud S, Russo CL, Tisdale A, Gipson IK. MUC16 mucin is expressed by the human ocular surface epithelia and carries the H185 carbohydrate epitope. Invest Ophtalmo \& Vis Sci. 2003;44:2487-95.

45. Davies JR, Kirkham S, Svitacheva N, Thornton DJ, Carlstedt I. MUC16 is produced in tracheal surface epithelium and submucosal glands and is present in secretions from normal human airway and cultured bronchial epithelial cells. Int J Biochem and Cell Biol. 2007;39:1943-54.

Ready to submit your research? Choose BMC and benefit from:

- fast, convenient online submission

- thorough peer review by experienced researchers in your field

- rapid publication on acceptance

- support for research data, including large and complex data types

- gold Open Access which fosters wider collaboration and increased citations

- maximum visibility for your research: over $100 \mathrm{M}$ website views per year

At BMC, research is always in progress.

Learn more biomedcentral.com/submissions 